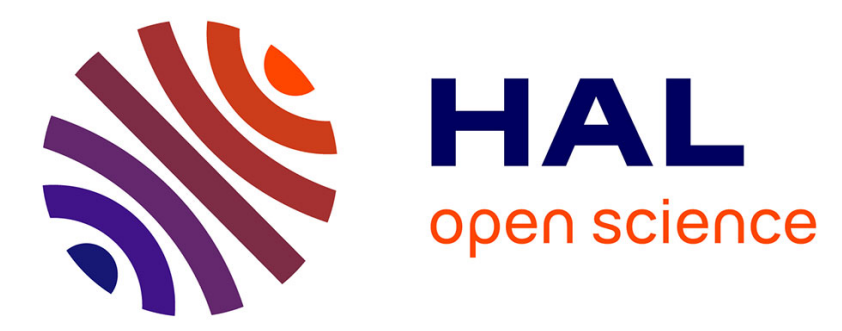

\title{
Stalking Resilience
}

Jose J. Gonzalez, Magnus Bång, Colin Eden, Raquel Gimenez, Josune Hernantes, Susan Howick, Patricia Maraña, Igor Pyrko, Jaziar Radianti, Amy Rankin, et al.

\section{- To cite this version:}

Jose J. Gonzalez, Magnus Bång, Colin Eden, Raquel Gimenez, Josune Hernantes, et al.. Stalking Resilience. 1st International Conference on Information Technology in Disaster Risk Reduction (ITDRR), Nov 2016, Sofia, Bulgaria. pp.31-45, 10.1007/978-3-319-68486-4_4 . hal-03213122

\section{HAL Id: hal-03213122}

\section{https://hal.inria.fr/hal-03213122}

Submitted on 30 Apr 2021

HAL is a multi-disciplinary open access archive for the deposit and dissemination of scientific research documents, whether they are published or not. The documents may come from teaching and research institutions in France or abroad, or from public or private research centers.
L'archive ouverte pluridisciplinaire HAL, est destinée au dépôt et à la diffusion de documents scientifiques de niveau recherche, publiés ou non, émanant des établissements d'enseignement et de recherche français ou étrangers, des laboratoires publics ou privés. 


\title{
Stalking resilience Cities as vertebrae in society's resilience backbone
}

\author{
Jose J. Gonzalez ${ }^{1}$, Magnus Bång ${ }^{2}$, Colin Eden ${ }^{3}$, Raquel Gimenez ${ }^{4}$, Josune Hernantes ${ }^{4}$, \\ Susan Howick ${ }^{3}$, Patricia Maraña ${ }^{4}$, Igor Pyrko ${ }^{3}$, Jaziar Radianti ${ }^{1}$, Amy Rankin ${ }^{2}$, and \\ Jose Mari Sarriegi ${ }^{4}$ \\ ${ }^{1}$ University of Agder, Centre of Integrated Emergency Management, Grimstad, Norway \\ \{jose.j.gonzalez, jaziar.radianti\}@uia.no \\ ${ }^{2}$ Linköping University, Dept. of Computer and Information Science, Linköping, Sweden \\ \{magnus.bang, amy.rankin\}@liu.se \\ ${ }^{3}$ University of Strathclyde, Dept. of Management Science, Glasgow, UK \\ \{colin.eden, susan.howick, igor.pyrko\}@strath.ac.uk \\ ${ }^{4}$ University of Navarra, Faculty of engineering (TECNUN), Dept. of Industrial Organization, \\ Donostia/San Sebastian, Spain \\ \{rgimenez, jhernantes, pmarana, jmsarriegi\}@tecnun.es
}

\begin{abstract}
This paper presents the EU H2020 project Smart Mature Resilience, which takes advantage of the fact that many cities are committed to become increasingly resilient and have ongoing processes for urban resilience. Smart Mature Resilience develops resilience management guidelines based on a Resilience Maturity Model that engages a growing number of stakeholders and multi-level governance in order for cities to become vertebrae for society's resilience backbone. In a dual approach, employing a systematic literature review of international resilience implementation approaches alongside group processes with experts, the Smart Mature Resilience project has developed a preliminary resilience maturity model consisting of five stages Starting, Moderate, Advanced, Robust and verTebrate (SMART) and a Systemic Risk Assessment Questionnaire. The SMART Resilience Maturity Model suggests two principal processes for the transition to resilience maturity: 1) A process of increasing engagement and collaboration with new stakeholder types, from local, to regional, to national to European in a growing resilience backbone, and 2) a process of quality improvement of policies for transitioning from a Safety-I to a Safety-II perspective (from risk assessment $\&$ mitigation to adaption to future surprises as conditions evolve).
\end{abstract}

Keywords: Resilience, Management guidelines, Critical Infrastructures, Natural disasters, Social dynamics, Maturity model, Risk systemicity.

\section{Introduction}

This paper reports findings done during the first year of the European Union's Horizon 2020 project Smart Mature Resilience (H2020-EU.3.7., project ref. 653569). The findings should be considered preliminary, since they will be subject to further refinement 
during the remaining two years of the project.

Smart Mature Resilience (SMR) was developed to meet the call "DRS-7-2014: Crisis management topic 7: Crises and disaster resilience - operationalizing resilience concepts". Altogether five out of forty nine proposals targeting this call were funded. SMR started 1 June 2015 and will finish 31 May 2018.

The call adopted the definition of resilience by the United Nations International Strategy on Disaster Risk Reduction (UNISDR): "The ability of a system, community or society exposed to hazards to resist, absorb, accommodate to and recover from the effects of a hazard in a timely and efficient manner, including through the preservation and restoration of its essential basic structures and functions" [1]. Based on this definition, the call stipulated:

- "It is necessary to break down and practically apply the UNISDR definition of resilience to different security sectors. Resilience concepts namely need to be developed for critical infrastructures (supply of basic services like water, food, energy, transport, housing/ shelter, communications, finance, health), but also for the wider public to integrate and address human and social dynamics in crises and disaster situations, including the role of the population, the media, rescuers (staff, volunteers and ad-hoc volunteers)."

- "A general resilience management guideline should be developed, linked with the European Union's Risk Assessment Guidelines, and operationalized in one or more of the security sectors, and/or the public."

- "The successful pilot implementation of the developed guideline needs to be demonstrated and tested in an operational environment."

To develop the SMR proposal we took the following stance:

1. To achieve society's resilience one must integrate cities' resilience in the overall perspective. Most people live already in cities, and cities will continue to grow at the expense of rural areas. When man-made or natural disasters happen, cities will always be affected, even if the disaster's epicentre should occur in rural areas.

2. Conversely, cities have the potential to play a key role for society's resilience: they have motivation and resources. Much has been done already and is being done about city resilience. However, the dominant perspective in those approaches is cities as isolated entities. Our project adds the perspective that society's resilience should rest on a resilience backbone with cities as vertebrae in the backbone.

3. Resilience should be seen as a quality improvement process, albeit a highly complex one, guided by a resilience maturity model. In this context a resilience maturity model should be understood as a trajectory through stages of increasing resilience maturity. The resilience maturity stages and the resilience building interventions ("policies") shape the resilience management guidelines required by the H2020's DRS-7-2014 call.

To achieve the goal of delivering a European emergent resilience backbone with cities as vertebrae, the SMR consortium was carefully composed of scientists and practitioner teams. The consortium consists of thirteen partners: four universities, two major 
non-profit organizations and seven cities.

The seven partner cities of the SMR project have excelled in their commitment as resilient cities or as smart cities. Four of the cities (Bristol and Glasgow - United Kingdom; Rome - Italy; and Vejle - Denmark) were selected by The Rockefeller Foundation as members of the 100 Resilient Cities (http://100resilientcities.org). The other three cities (San Sebastian - Spain; Kristiansand -Norway; and Riga - Latvia) have engaged in various smart city activities and networks.

The four universities in the consortium (Agder, Linköping, Navarra and Strathclyde) complement and supplement each other in terms of expertise and methods so as to cover all the relevant aspects of the project research. A major asset for the purpose of conducting pilot implementations of the envisioned resilience management guideline was the fact that three of the universities resided in cities represented in the project consortium (viz. Kristiansand for University of Agder, Donostia/San Sebastian for the University of Navarra and Glasgow for the University of Strathclyde).

Finally, the SMR consortium included two organizations with critical expertise for the success of the project, viz. ICLEI and DIN.

"ICLEI - Local Governments for Sustainability" http://www.iclei.org/ defines itself as «a high-energy, flexible Movement of local governments working together in national, regional and international networks; engaging in global campaigns for sustainability, participating in performance-based programs, advancing through an international exchange of experiences and solutions - a movement which is supported by commitment processes, performance frameworks, programs, networks, strategic alliances and centres of excellence.». In the SMR project ICLEI leads the pilot implementation work package. In addition, ICLEI leads the work package that targets dissemination and project impact.

DIN, the German Institute for Standardization, is one of the most active standards organizations in the world. In the SMR project DIN prepares the ground to develop international standards emerging from the project.

The paper continues in Section 2 with a discussion of the project's approach in terms of a maturity model. In Section 3 we provide an overview of the SMR project's architecture. Section 4 presents the main insights from the project's worldwide literature survey on resilience. Section 5 describes our current understanding of the resilience maturity model. Section 6 concerns the development of the Systemic Risk Assessment Questionnaire. We conclude in section 7 with a brief summing up.

\section{Advantages of a maturity model for resilience}

Maturity models emerged from quality improvement in software engineering in 1979. In the meantime maturity models have been developed for more than twenty different application areas [2]. To the best of our knowledge, the SMR project embodies the first attempt to develop a maturity model for society's resilience.

Beyond the rationale that a resilience maturity model contains key aspects of the resilience management guidelines required by the H2020 DRS-14-2014 call, proceed- 
ing in terms of a resilience maturity model has a key advantage: It facilitates the otherwise extremely difficult requirement to develop and test in an operational environment the pilot implementation of the resilience management guideline.

Achieving resilience within the scope of a three year project that, as a first step, must develop the tools to achieve resilience, is hardly possible. The partner cities in the SMR project were carefully selected so that the cases for demonstrating and testing the resilience management guideline concern cities in different stages of maturity.

First, a preliminary resilience maturity model was developed, shown in Table 1 . The SMART acronym maturity model corresponds to the first letters of the maturity stages Starting - Moderate - Advanced - Robust and the T from the last stage Vertebrate.

Table 1. Preliminary resilience maturity model

\begin{tabular}{ll}
\hline Maturity Stage & Description \\
\hline Starting & The city has launched policies regarding resilience development. The \\
risk assessment is still fragmented and incomplete with regard to haz- \\
ards affecting critical infrastructures and man-made threats. The com- \\
munity involvement and the private-public cooperation are incipient. \\
The approach is mainly city centered. A multi-governance approach \\
with a European dimension is dormant. The city is not part of a larger \\
resilience network. \\
The city manages resilience development policies, using control \\
measures. The risk assessment with regard to hazards affecting critical \\
infrastructures and man-made threats are been operationalized in co- \\
operation with critical infrastructure providers. Plans to involve com- \\
munities and develop private-public cooperation have been developed. \\
The city recognizes the relevance of a multi-governance approach with \\
a European dimension and acts to invigorate the approach. The resili- \\
ence management is still fragmented and siloed. The city has started \\
planning for networking with other European cities with regard to re- \\
silience and sustainability. \\
The city has developed a framework to manage resilience within an \\
explicit holistic approach that integrates critical infrastructure provid- \\
ers, expertise on man-made disasters and sustainability. Community \\
resilience and private-public cooperation is part of the approach. The \\
nodes in a multi-governance approach with a European dimension are \\
well-linked in the plans, but not yet fully operationalized. The city is \\
member of a major network of European cities with regard to resilience \\
and sustainability. \\
The city has engaged all relevant agents to its resilience holistic ap- \\
proach. Agents perceive value added by resilience. The multi-govern- \\
ance approach with a European dimension is well developed and oper- \\
ationalized. The city is a member in a major network of European cities \\
with regard to resilience and sustainability, with a proactive posture \\
regarding interdependencies and potential cascading effects. \\
The city excels with its resilience as part of the ecosystem (regional, \\
national, European) resilience. The city acts as a vertebra in the Euro- \\
pean Resilience backbone
\end{tabular}


Note the increase of the cities" capability as functional units ("vertebrae") of the resilience backbone as they progress toward higher resilience maturity levels.

Next, a preliminary assessment of the resilience maturity of the partner cities was done. The outcome yielded that Donostia/San Sebastian was at the resilience maturity stage "Moderate", Kristiansand at the stage "Advanced" and Glasgow at the stage "Robust". The project target is to demonstrate and validate that each city will progress to the next higher stage of resilience maturity. Thus the SMR project is structured so that much of the trajectory toward resilience, from low to high stages, is covered.

\section{Overview of the Smart Mature Resilience proposal}

The SMR project was conceived with the perspective of a holistic, multi-level governance perspective of European resilience with cities as vertebrae in a strong European resilience backbone. SMR builds upon the experience, the insights and the practice of on-going endeavours on urban/city resilience (including smart cities), but it approaches risk and resilience in an overall European perspective. The project does not view cities as isolated entities, but rather as interconnected and interdependent units, in the similar situation of vertebrae as interconnected and interdependent parts of a backbone. Cities can be affected directly or indirectly by disasters. Indirect effects can arise from proximity, from interdependencies and cascading effects, or even from sharing the same class of major threats and suggesting common approaches and collaborative arrangements.

Error! Reference source not found. illustrates the vision of a resilience backbone in Europe with cities as vertebrae. SMR targets an emergent resilience backbone consisting of the cities in the consortium as a direct project result. Furthermore, the project develops the tools and triggers a process to facilitate growth of the resilience backbone by attracting and consolidating more cities in the resilience backbone.

Error! Reference source not found. illustrates that the Resilience Management Guideline rests on three pillar tools (Resilience Maturity Model, Systemic Risk Assessment Questionnaire and Resilience Building Policies). The Engagement and Communication Tool ensures active user participation. The System Dynamics model is a computer simulation that integrates and connects the tools, supporting decision makers to diagnose and monitor with "what-if" analysis the progress to higher resilience maturity levels.

The activities during the first year of the project enhanced the preliminary resilience maturity model presented in Error! Reference source not found. and a prototype of the Systemic Risk Assessment Questionnaire. In addition, design principles and specification for the Engagement and Communication Tool were derived.

The enhanced resilience maturity model was the outcome of two parallel project activities: 1) a thorough survey of the literature on resilience, followed by a literature synthesis and experts' assessment of the findings using a Delphi process; and 2) workshops with experts on critical infrastructure, climate change, social dynamics and city representatives occurring in Riga, Bristol, Rome and Vejle. The prototype of the Systemic Risk Assessment Questionnaire evolved from activities using Group Explorer 
(See https://www.strath.ac.uk/media/faculties/business/brochures/GE_Brochure.pdf) during the workshops mentioned above.

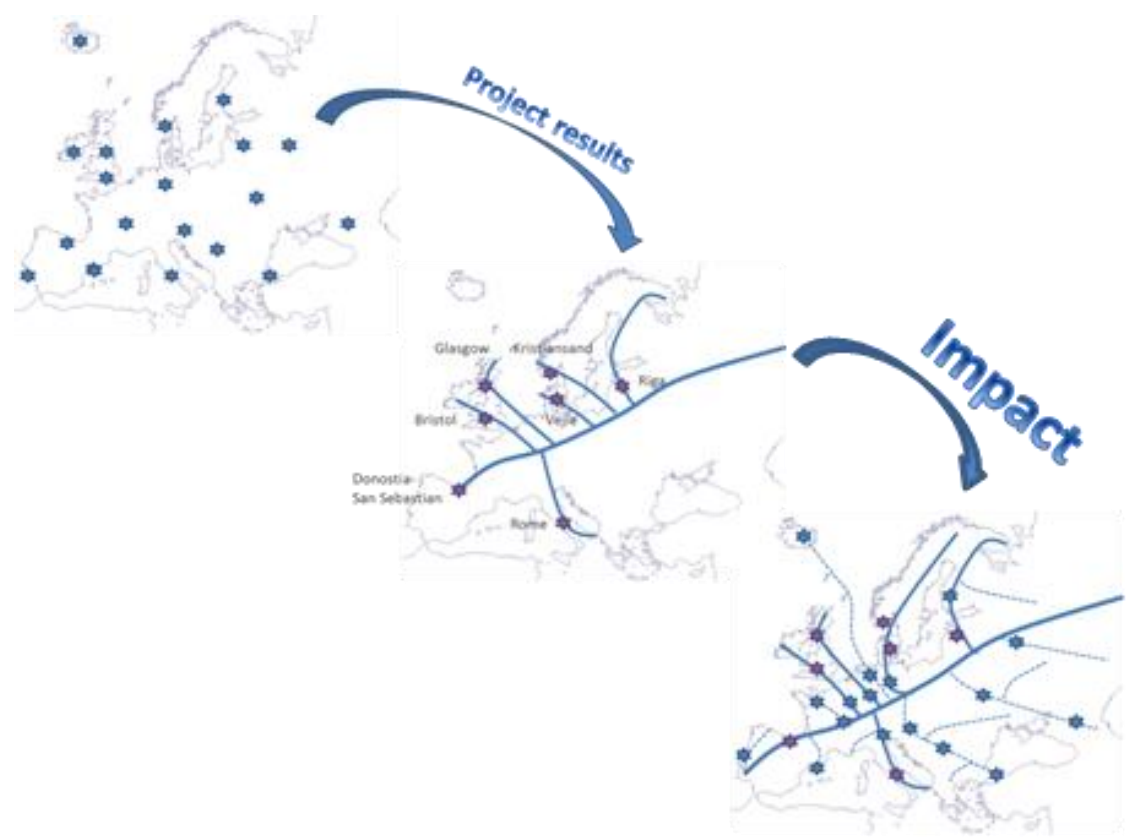

Fig. 1. The vision of an emergent resilient backbone in two stages: as direct project result and as long-term impact of the project

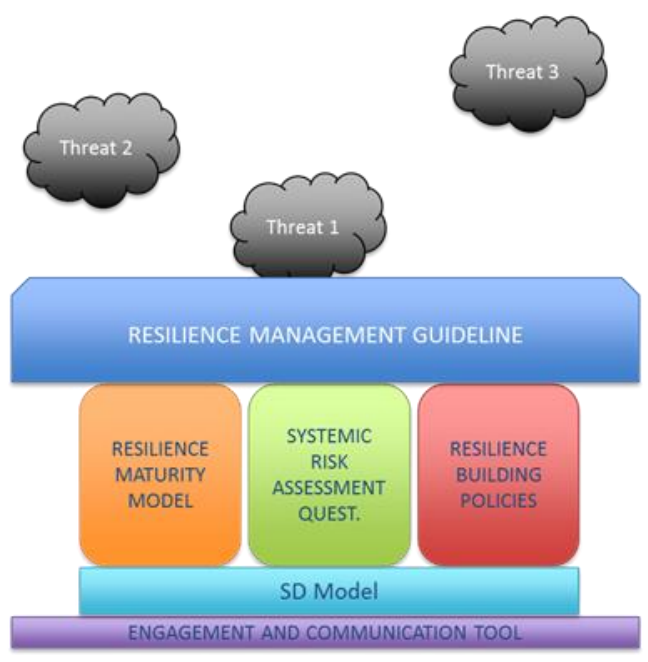

Fig. 2. Tools supporting the resilience management guideline 


\section{Resilience Literature Survey}

A worldwide literature survey of state-of-the-art resilience research was carried out to inform the development of the resilience management guideline and ensure common ground of concept, methods and approaches throughout the project. The survey was in part worldwide and general, and in part focused on Europe and specific problem areas. The aim was to identify, synthesize and assess the main challenges and best practice existing today. Further, the survey serves as a repository of policies, metrics and best practices for continued work in the project.

The literature survey encompassed several reviews which can be summarized as follows: (1) a systematic literature review of academic peer-reviewed journal articles on urban resilience (119 articles), (2) a systematic literature review of three problem areas (resilience in critical infrastructure, climate change and social dynamics) (38 articles), (3) a review of EU project reports regarding resilience (170 reports) (4) a review of approaches and methods in relevant organisational bodies and networks (23 reports), (5) a survey of approached used in the SMR project cities (7 questionnaires).

The main findings of the resilience literature survey can be summarized as follows:

\subsection{There are different perspectives on the concept of resilience}

An analysis of underlying assumptions and differences in definitions of urban resilience uncover four conceptual "tensions", that is, theoretical concepts which are inconsistent or unclear. (1) "The notion of equilibrium". The concept of an equilibrium makes the distinction between resilience as the ability to "bounce back" or retain functionality in the face of disturbance [3] compared to definitions that have a multi-equilibrium view, or see resilience as adaptive cycles, emphasizing the systems' ability to adapt, learn and change $[4,5]$. (2) "Resilience behaviours". Comparisons between the behaviours that characterise resilience uncover different theoretical underpinnings and thus pose a challenge when used concurrently in definitions. For example, "recover" suggests that there is an objective to "get back" to a previous state, "absorb" suggests coping with a disturbance without changing the basic structure and "adapt" suggests a change in structure to cope with new demands. (3) "Temporal aspects", that is, differences in how resilience is described; as something that happens before, during or after some disturbance. The differences imply the need for different types of policies and strategies, e.g., do they focus on building stable structures (before), flexible response teams (during) or re-building (after)? (4) "Urban resilience boundaries". Defining boundaries for the system to be examined presents a challenge which is not well discussed in literature, nor described in the reviewed urban resilience definitions. Boundaries include, for example, geographical (city or region limits), temporal, sectors of inclusion and level of abstraction.

\subsection{A shift in resilience tools from theory to practice}

The literature review shows that frameworks for urban resilience are abstract and far from being a practical tool for operationalization. There is a large variety in the attrib- 
utes/indicators used in the frameworks, which reflects a lack of consensus and unification on the notion of urban resilience in general and the central concepts is relates to. The findings further reflect the vast number of aspects that are important to resilience in an urban context and that there are many ways to increase resilience, depending on the area of interest. In developing guidelines for resilience it is thus of importance to carefully consider how to go from general concepts to specific applications. Each city that applies the maturity model is unique and thus a model which encompasses a large number of variables is necessarily on a high level. However, guidance on how general concepts can be applied in context may be a useful part of developing guidelines to aid the implementation. This could be, for example, support on how to priorities more/less important parts of the model to a particular context and also to demonstrate how different aspects of the model are interlinked.

\subsection{Political and financial support and social engagement}

The literature suggests that the financial and political capital of a city is a critical factor for resilience management. Challenges related to urban resilience are in many cases related to gaining support and financing resilience-supporting measures. Further, as found in the SMR partner city survey, a difficulty is that much of the policy and related decision-making regarding resilience is outside the cities' jurisdiction, which inhibits their response to disasters and crises. The dependencies, numerous stakeholders (subcontractors) and legal frameworks render managing the infrastructures on the local level difficult. A present strategy in the resilience work by the partner cities, as demonstrated in the survey, is to improve communication among different stakeholders and to pool resources locally and regionally. The strategy was echoed in the literature review as a central factor for successful implementation of policies.

Another influencing element of urban resilience is citizens as local communities. Strategies to increase resilience include having well-informed citizens and promoting self-protective behaviour. Involving local stakeholders also has the benefit of building trust in a community and identifying local needs, which in turn may increase the resilience of a community. To create resilience, it is not sufficient to create new policies at a high level, it is also critical to have support from the community in order to make changes. These enabling factors should be considered in the development of the maturity model.

\subsection{There is a need to link resilience and governance}

In the literature, resilience is often linked to governance concept although the use and context of governance itself varies among scholars, especially in how it operates in society [6]. However, there are common themes, including adaptiveness, adaptive capacity and multi-level governance [6 - 9]. Adapting from Commission of Global Governance (CGC), governance is interpreted as "the sum of the many ways individuals and institutions, public and private, manage their common affairs" [10]. Governance is a continuous process, requiring cooperation and capacity to accommodate conflicting or diverse interests. It consists of formal institutions and regimes empowered to enforce 
compliance, as well as informal arrangements that people and institutions either have agreed to or perceive to be in their interest. In brief, adoption of governance implies several aspects: 1) Institutional pluralism and networks beyond the state established through cooperation of multiple actors and partnerships, distributed responsibilities. 2) No longer single sovereign authority. 2) New form of authority and control based on diplomacy, agreements, and empowerments. 3) Multilevel governance and issues of scale such as how much it is possible to talk on a widespread cross-national shift and trend [6].

The concept of resilience within governance of institutions and organisation is relatively new, and the Hyogo Framework Action (HFA) 2005-2015 has pushed the resilience agenda forward in governance circles. Governance is important because governments often cannot act alone to respond to specific disaster events. When linking governance to the city resilience, it suggests that a resilient city should be capable of sustaining multi-level, multi-stakeholders platform to promote resilience in different levels: regional, national and international. At a more advanced maturity level, organizational capacities of the city to negotiate and make agreement are required. Principles of good partnership are becoming relevant such as shared vision, consensus, participation, negotiation, inclusion, volunteerism, accountability, and trust [11].

\subsection{Managing risk in a governance context}

Incorporation of resilience into governance means that an increased numbers of actors such as politicians, regulators, businesses, NGOs, media and the public are involved in common affairs. The literature points out the importance of taking into account risks of collaborative practice in governance, and wider social and political context [8], [11]. Risk governance is a comprehensive way of understanding and dealing with risks from different sources of hazards, including all relevant actors and stakeholders, who have to deal with the effects and impacts of the respective risks [7]. When a city adopts multilevel governance approach on a common issue, it should be followed by an understanding of the advantages and disadvantages of this concept such as unclear responsibility or accountability and many other consequences that may follow. Partnership in risk management is considered as a way of risk governance [7]. One strategy is to establish public-private insurance systems against unexpected events such as natural disasters, to enable risk sharing cooperation through public-private partnerships.

\section{The enhanced Resilience Maturity Model}

The principal aim of the second work package of the SMR Project is to gather requirements from partner cities regarding resilience based on their current experience and expectations in order to enhance the preliminary version of the Resilience Maturity Model (Table 1) as well as gathering information for the other tools (see Fig. 2).

The SMR project focuses on resilience on three different topics: 1) risks and problems derived from critical infrastructures and technology dependencies, 2) climate change and the resulting increase of natural disaster risks, and 3) human dynamics such 
as, immigration, poverty, population aging and dependencies problems. Work-shops on these topics with the partner cities and their stakeholders enabled the project to understand better partner cities' requirements regarding resilience as well as to orient the outcomes of the project to cities' needs. The collected information was used to enhance the preliminary version of the Resilience Maturity Model with indicators and policies.

Four workshops with partner cities and local stakeholders were organized to gather their requirements regarding the resilience building process. The first workshop, held in Riga 26- 29 October 2015, focused on the analysis of the partner cities' dependency towards critical infrastructures and technology. The second workshop, held in Bristol 25- 28 January 2016, collected information on risks associated with climate change. The third workshop, held in Rome 22- 25 February 2016, analysed social problems. Finally, a workshop was held in Vejle 9- 12 May 2016 with the aim to explore the partner cities' current experiences, best practices, and difficulties concerning the resilience building process.

In all the workshops the different challenges that the cities are facing were also discussed. Further, the possible policies and actions that could be carried to overcome potential barriers were identified. As a result, a great range of resilience building policies were identified, in addition to useful requirements for the development of the SMR tools.

The workshop sessions were also very helpful to create a collaborative and supportive environment between the scientific partners (universities, ICLEI and DIN) and the cities, building trust among them and therefore, increasing their involvement in addition to giving the opportunity of mutual learning.

Two different methodologies were used during these workshops: Group Explorer (GE) and Group Model Building (GMB). For details on GE see the next section.

Group model building (GMB) is a collaborative methodology that enables integrating fragmented knowledge, initially residing in the minds of different agents, into aggregated models [12]. GMB encourages consensus building among the involved agents. Actually, the GMB methodology has specific exercises where the group of experts is usually divided into small groups, and then the results obtained are exposed in plenary in order to encourage the discussions between different problem perspectives that enrich the process and lead to reach a consensus.

The information collected from the GMB exercises with partner city representatives and stakeholders during the four workshops was analysed and combined with results from the worldwide literature survey on resilience. This enhanced and refined the preliminary Resilience Maturity Model from Table 1. Thereafter, a Delphi process provided additional insights and feedback concerning the Resilience Maturity Model, leading to an even more refined version.

Table 2 shows the high-level structure of the maturity model. The dots indicate text with details about the corresponding entry (e.g. detailed descriptions of the resilience maturity stages and resilience building policies).

The policies contained in the maturity model are generic, bearing in mind that the maturity model will be in charge of supporting activities at a strategic level. Therefore, the policies described in each maturity stage are described using a high-level approach, 
while in the policy repository tool the policies are particularized for each city. The policies we classified along five resilience dimensions that were elicited from the workshop participants using the GMB method: Robustness of infrastructure \& Resources, Preparedness, Leadership \& Governance, Cooperation and Learning.

Table 2. Structure of the enhanced Resilience Maturity Model

\begin{tabular}{|c|c|c|c|c|c|c|}
\hline & \multicolumn{5}{|c|}{ MATURITY STAGES } \\
\hline & & Starting & Moderate & Advanced & Robust & verTebrate \\
\hline & $\begin{array}{r}\text { Maturity stage } \\
\text { description }\end{array}$ & $\ldots$ & $\ldots$ & $\ldots$ & $\ldots$ & $\ldots$ \\
\hline \multirow{5}{*}{ 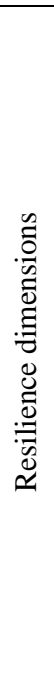 } & $\begin{array}{l}\text { Robustness of } \\
\text { infrastructure \& } \\
\text { Resources }\end{array}$ & $\begin{array}{l}\text { Policies } \\
\text { correspond- } \\
\text { ing to the } \\
\text { Starting Stage } \\
\text { Related to the } \\
\text { Robustness of } \\
\text { infrastructure } \\
\& \text { Resources } \\
\text { dimension }\end{array}$ & $\ldots$ & $\ldots$ & $\ldots$ & $\ldots$ \\
\hline & Preparedness & $\ldots$ & $\ldots$ & $\ldots$ & $\ldots$ & $\ldots$ \\
\hline & $\begin{array}{l}\text { Leadership \& } \\
\text { Governance }\end{array}$ & $\ldots$ & $\ldots$ & $\ldots$ & $\ldots$ & $\ldots$ \\
\hline & Cooperation & $\ldots$ & $\ldots$ & $\ldots$ & $\ldots$ & $\ldots$ \\
\hline & Learning & $\ldots$ & $\ldots$ & $\ldots$ & $\ldots$ & $\begin{array}{l}\text { Policies } \\
\text { corresponding } \\
\text { to Vertebrate } \\
\text { Stage related } \\
\text { to the Learn- } \\
\text { ing dimension }\end{array}$ \\
\hline
\end{tabular}

While we expect that the project work in the second and the third project year will help improve and refine the content of the model - in terms of the model policies - the overall structure of the Resilience Maturity Model after the first project year as shown in Error! Reference source not found. is likely to remain quite stable.

Rather than providing a detailed description of the identified policies - which would require much space - we render on Error! Reference source not found. a tentative insight emerging from project work done so far. (Needless to say, the policies and the tentative insight will be subjected to critical analysis during the implementation of the resilience pilot in the second year of the project.)

\section{The Systemic Risk Assessment Questionnaire}

"Resilience .... requires actively understanding the risk landscape." [13]

This quote highlights that a key element of resilience is an ongoing risk assessment. Cities which are mature with respect to resilience should therefore be actively assessing 
the different types of risks which impact them and the impact of policies to mitigate such risks. In addition, as cities become more mature, there will be increasing engagement with key stakeholders. Therefore risk assessment and mitigation tools are required that can take account of the perspective of a wide variety of stakeholders involved in city resilience, consider how risks and stresses impact the cities level of resilience and which mitigation policies best support their resilience journey. In addition, the development of city resilience is inevitably constrained by finite resources, and therefore it is important for cites to prioritise risks and stresses in order to get value for money through cost-benefit analysis.

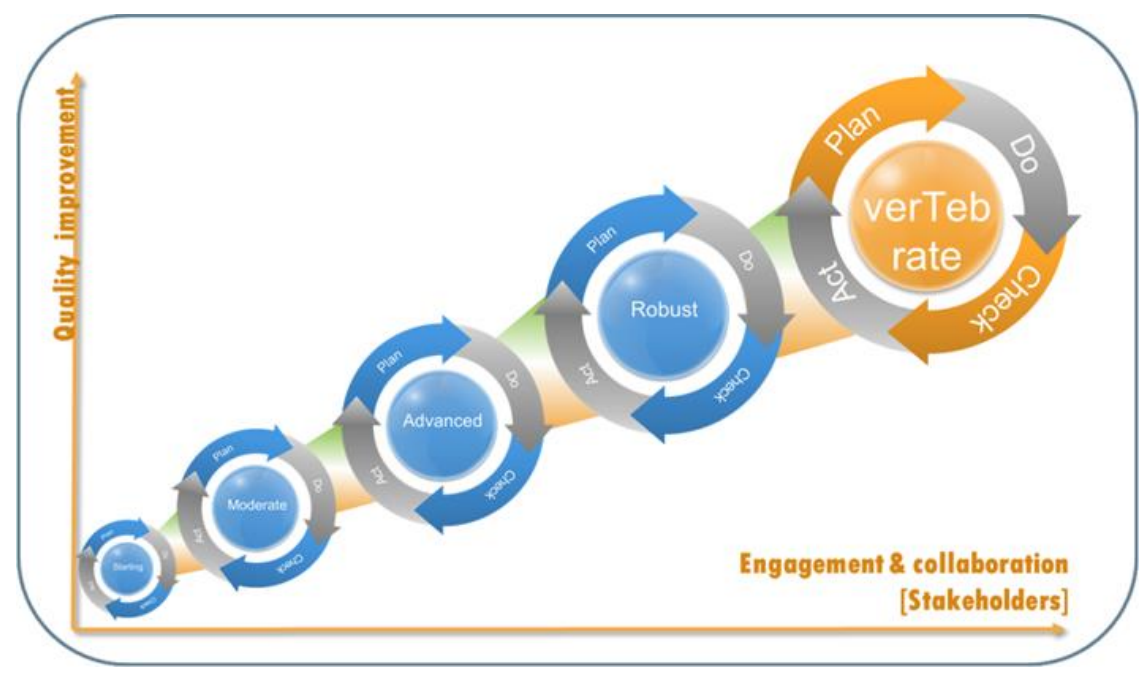

Fig. 3. The contents of the enhanced Resilience Maturity Model with two principal dimensions: $\mathrm{x}$-axis) Engagement and collaboration with more stakeholder categories (local, regional, national, European); y-axis) Continuous quality improvement within each maturity stage, increasing in scope as the city progresses to higher stages of resilience maturity

Recent research [14-17] indicates that it is the interaction and dynamics between different types of risk that can cause the most damage to, for example, a project or a city. Risk and stresses are likely to interact with one another and form a portfolio where the impact of the whole is greater than the sum of the parts. When one risk event is triggered, it may reinforce the likelihood and ramifications of other risks or stresses, [16], as well as form interacting vicious cycles where risk consequences mutually feed themselves [18]. In contrast to traditional risk registers where risk are treated as independent [17], by recognising the systemicity of risks, it is possible to identify and address those risk or stresses which seem most potent in triggering and reinforcing negative ramifications within the risk landscape.

As a result, the risk systemicity perspective calls for the introduction of new tools and approaches to managing risks, which allow multiple stakeholders to surface and negotiate their understandings of the relationships between relevant risk and stresses with respect to the city [18]. 
A tool which encompasses the systemic perspective on risks is the Systemic Risk Assessment Questionnaire which has been used successfully in the context of risks assessment in projects within a large company in the private sector [16]. The Systemic Risk Assessment Questionnaire is an interactive questionnaire programmed in Excel using Visual Basic for Applications which comprises a set of questions about the relationships between risks. The questions in the Systemic Risk Assessment Questionnaire seek to gain stakeholders judgements regarding the risks they face. However, the questions are not independent from one another, instead they capture the interdependence between risks through, for example, removing risks that become irrelevant or giving increased weight to some risks due to responses to questions regarding other risks. The output of the questionnaire is a risk score which helps in assessing the risk level of a given project or initiative and provides help in prioritising those areas where most attention is required.

The Systemic Risk Assessment Questionnaire is therefore being developed for the needs of the SMR project. The initial work on the Systemic Risk Assessment Questionnaire construction was grounded in a series of group workshops organised with representatives of the seven European cities involved in SMR. Each of the workshops was dedicated to one of the themes being covered by the SMR project: critical infrastructure, climate change, and social problems. The aim of the sessions was to gather views and opinions from city representatives with regards to risks associated with each theme. These views were gathered using a Group Explorer decision support system to facilitate group discussion and negotiation about risks [19,20]. The system allowed for surfacing and gathering the perspectives of multiple stakeholders in a fair and structured manner [18]. The entire process was facilitated by an academic representative who, at various stages of the session, invited participants to engage in different types of exercises, such as consideration of risk that may impact their cities, identification and prioritisation of key risk themes, and gathering of policies which address the identified risks. The resulting empirical data formed a risk map including over 2000 concepts and links which depicted complex relationships between risk events and their ramifications, as expressed by city participants.

Drawing on the analysis of the risk map created by workshop participants, the researchers seek to generate a list of risks scenarios which will form the basis of the Systemic Risk Assessment Questionnaire. When using the Systemic Risk Assessment Questionnaire, respondents will be asked to answer questions about the likelihood of the risk scenarios and the risks which trigger them with respect to their own cities. In order to provide an indication of the overall level of risk in a city, risk scenarios will also be weighted with respect to the potential impact of the scenarios if they were to occur. These weights will be informed by the analysis of the maps produced during the workshops and will be validated with city participants in two further workshops.

As indicated above, a key outcome from the Systemic Risk Assessment Questionnaire is to assist in the prioritisation of managing risks and stresses. It will also provide a tool that can be used to engage multiple city stakeholders in considering those risks which impose the greatest threat on a city, creating potential barriers to resilience, and to agree upon the most important areas to prioritise policies. 


\section{$7 \quad$ Concluding remarks}

SMR is an ambitious project, but as evidenced in this paper, good progress has al-ready been done in its first year.

The close collaboration between the scientific partners and city partners has al-lowed to create an intellectually stimulating environment which translates into better understanding of resilience.

Following the lessons from the literature, the project partners have aimed to translate the general concepts into practical applications, as well as to address the "theoretical tensions' around resilience; this is evidenced in the city resilience tools which are described in this discussion. It can be argued that the co-creation of the city resilience tools by both the scientific partners and city partners at the same time helps to achieve the balance between 'the general' (conceptual level) and the 'specific' (operational level).

Whilst the development of tools has proved to be a collaborative process for the SMR partners, it is expected that the same level of collaboration will be sustained as the project enters its second year when the city resilience tools will be implemented in the participating cities.

\section{Acknowledgement}

The Smart Mature Resilience research project has received funding from the European Union's Horizon 2020 research and innovation programme under grant agreement no.653569.

\section{References}

1. UNISDR, UNISDR Terminology on Disaster Risk Reduction. International Strategy for Disaster Reduction (ISDR), pp. 1-30 (2009).

2. Wendler, R.: The maturity of maturity model research: A systematic mapping study. Information and Software Technology 54, 1317-1339 (2012).

3. Bruneau, M., et al.: A Framework to Quantitatively Assess and Enhance the Seismic Resilience of Communities. Earthquake Spectra 19(4), 733-752 (2003).

4. Walker, J., Cooper, M.: Genealogies of resilience: From systems ecology to the political economy of crisis adaptation. Security Dialogue 42(2), 143-160 (2011).

5. Malalgoda, C., D. Amaratunga, Haigh, R.: Challenges in Creating a Disaster Resilient Built Environment. Procedia Economics and Finance 18, 736-744 (2014).

6. Walker, G., et al.: Risk governance and natural hazards. CapHaZ-Net FP7 Project (2010).

7. Costa, M.M., et al.: Governance Indicators for (Un)succcesful MSPs (2013).

8. Renn, O.: Risk Governance: Coping with Uncertainty in a Complex World. Natural Hazards, 48(2), p. 313 (2008).

9. Crowe, P., Foley, K.: The Turas Project: Integrating Social-Ecological Resilience and Urban Planning: TURAS FP7 Project. pp. 1-15 (2013).

10. CGG, Our Global Neighbourhood. Oxford, UK: Oxford University Press (1995). 
11. McLean, L., Guha-Sapir, D.: Developing A Resilience Framework. Vol. 2015, ENHANCE FP7 Project (2013).

12. Vennix, J.A.M.: Group model building: facilitating team learning using system dynamics. Chichester, Wiley (1996).

13. Van der Vegt, G.S., et al.: Managing Risk and Resilience. Academy of Management Journal 58, 971-980 (2015).

14. Williams, T.M.: Systemic project risk management - the way ahead. Journal of Risk Assessment and Management, 1(1-2), 149-159 (2000).

15. Williams, T.M., Ackermann, F., Eden, C.: Project risk: systemicity, cause mapping and a scenario approach, in Managing Risks in Projects., K. Kahkonen and K. Artto, Editors. E\&FN Spon: London, UK (1997).

16. Ackermann, F., et al.: Systemic Risk Assessment: A Case Study. The Journal of the Operational Research Society 58, 39-51 (2007).

17. Eden, C., et al.: The role of feedback dynamics in disruption and delay on the nature of disruption and delay (D\&D) in major projects. Journal of the Operational Research Society 51, 291-300 (2000).

18. 18. Ackermann, F., et al., Systemic risk elicitation: Using causal maps to engage stakeholders and build a comprehensive view of risks. European Journal of Operational Research, 2014. 238: p. 290-299.

19. Ackermann, F., Eden, C.: Using Causal Mapping with Group Support Systems to Elicit an Understanding of Failure in Complex Projects: Some Implications for Organizational Research. Group Decision and Negotiation 14, 355-376 (2005).

20. Ackermann, F., Eden, C.: Making Strategy: Mapping Out Strategic Success, London, UK: Sage (2011). 